\title{
The Effect of Postoperative Early Mobilization on the Healing Process and Quality of Life Following Radical Cystectomy and Ileal Conduit: A Randomized Prospective Controlled Trial
}

\author{
(D) Sevgi Vermişli1, (1) Özgür Çakmak2, (1) Talha Müezzinoğlư3, (1) Güven Aslan4, (1) Hakan Baydur5 \\ ${ }^{1}$ Republic of Turkey Ministry of Health, Bornova Türkan Özilhan State Hospital, İzmir, Turkiye \\ 2Medicana International İmir Hospital, Clinic of Urology, İzmir, Turkiye \\ 3 Manisa Celal Bayar University, Hafsa Sultan Hospital, Clinic of Urology, Manisa, Turkiye \\ ${ }^{4}$ Dokuz Eylül University Training and Research Hospital, Clinic of Urology, İzmir, Turkiye \\ 5 Manisa Celal Bayar University Faculty of Health Sciences, Manisa, Turkiye
}

\section{What's known on the subject? and What does the study add?}

Early and organized mobilization after surgery is in the context of enhanced recovery after surgery interventions. However, there is no clear data about the time of early mobilization. This mobilization procedure can be performed safely. Early mobilization could be safely performed in the patients who underwent radical cystectomy and ileal diversion in accordance with following the standard procedure and it, which has positively contributed to the healing process and improved their quality of life.

\section{Abstract}

Objective: This study aimed to evaluate the effect of postoperative early mobilization in patients who underwent radical cystectomy (RC) and ileal conduit in terms of the healing process and quality of life (QoL).

Materials and Methods: This multicenter prospective randomized controlled study included 40 patients who were randomly divided into two groups. The intervention group was mobilized within the first $16 \mathrm{~h}$ postoperatively following the mobilization procedure, which was determined according to the literature. Data were collected using the case report form, hospital anxiety and depression scale, and 36-Item Short Form Survey (SF-36) QoL scale.

Results: Postoperative hospitalization, narcotic analgesic administration duration, first oral food intake, flatus, defecation, and nasogastric tube termination time were shorter in the intervention group. Additionally, blood glucose and pulse values were higher in the control group after mobilization. SF-36 physical function, physical role difficulty, and general perception of health subscales were higher in the intervention group at the postoperative first and third months $(p<0.05)$.

Conclusion: Early mobilization positively contributed to the healing process and improved the QoL in patients who underwent RC and ileal conduit surgery.

Keywords: Early mobilization, radical cystectomy, ileal conduit, quality of life

\section{Introduction}

Radical cystectomy $(\mathrm{RC})$ is considered a standard treatment option for invasive and high-risk recurrent non-invasive bladder cancer (1). RC is one of the most traumatic cancer surgeries in terms of psychological stress and lifestyle change (2).
Today, interest is growing in quality of life ( $\mathrm{OoL}$ ) studies that evaluated the symptomatic effects of oncological surgical modalities considering the patients' subjective statements (1). Negative changes are observed regarding urinary, rectal, and sexual functions and in the perception of body image in patients undergoing $\mathrm{RC}$ and urinary diversion (3). Minimizing the loss

Correspondence: Ph.D., RN Sevgi Vermişli, Republic of Turkey Ministry of Health, Bornova Türkan Özilhan State Hospital, İzmir, Turkiye

Phone: +90 5332240043 E-mail: sevgi0535@yahoo.com ORCID-ID: orcid.org/0000-0002-5306-6519

Received: 24.05 .2021

Accepted: 01.08.2021

Cite this article as: Vermişli S, Çakmak Ö, Müezzinoğlu T, Aslan G, Baydur H. The Effect of Postoperative Early Mobilization on the Healing Process and Quality of Life Following Radical Cystectomy and Ileal Conduit: A Randomized Prospective Controlled Trial. J Urol Surg, 2022;9(1):9-19.

๑Copyright 2022 by the Association of Urological Surgery / Journal of Urological Surgery published by Galenos Publishing House. 
of function as a result of surgical intervention is possible with evidence-based treatments (4).

Most of the enhanced recovery after surgery (ERAS) protocols are physiologically based on preoperative, operative, and postoperative procedures that can be adapted to a specific problem (5). Early and organized mobilization after surgery is in the context of ERAS interventions (6). Nowadays, ERAS is still limited in clinical practice despite the evidence of its efficacy in patients who underwent RC and urinary diversion $(7,8)$. In their meta-analysis, Cerantola et al. (9) revealed that the evidence of the effectiveness of many ERAS components on RC treatment is insufficient. Early mobilization has been provided for patients who received RC treatment; however, standard mobilization procedure was not defined in the ERAS protocol studies $(10,11)$. To our knowledge, our study is the first prospective randomized controlled study that evaluated the effect of early mobilization on clinical outcomes and $\mathrm{QoL}$ in patients who underwent RC and urinary diversion. This study aimed to investigate the effects of early mobilization on the postoperative healing process and QoL in patients who underwent $\mathrm{RC}$ and ileal conduit surgery due to bladder cancer. This study highlights the need to increase the healthcare professionals' awareness of the importance of ERAS protocol and ERAS components on the healing process of patients who received $\mathrm{RC}$ and ileal loop.

\section{Materials and Methods}

\section{Design}

A prospective randomized controlled study.

\section{Research Model}

This study was conducted between March 2015 and April 2017 as multicenter research within the body of the Urooncology Association at an educational research hospital and two university hospitals serving in the Aegean region of Turkey. The sampling was determined following the study conducted by Porserud et al. (10), which was conducted with two groups consisting of 20 individuals by block randomization. The sample size of the study was determined by power analysis following Porserud et al. (10). According to the power analysis results, 40 patients were included in the study and were divided into two groups of 20 patients by block randomization, as intervention and control groups. Patients who were hospitalized to receive $\mathrm{RC}$ and ileal loop treatments were included in the study; the individuals were aged 50-75 years, literate, and open to communicate and cooperate, without sensory loss or comorbidity that could hinder mobilization and history of radiotherapy and chemotherapy and were in American Society of Anesthesiologists I-II risk groups, and did not have any mental and psychiatric disorders. Those who signed the informed consent form were included in the study. During the study, 2 patients could not be followed due to communication problems, 3 patients developed intolerance symptoms during mobilization, and 12 patients underwent additional surgical procedures; a total of 17 patients were excluded from the study. Patient recruitment went on until the number of sampling was reached. After exclusion of 17 patients, the study was ended when a total of 40 patients (intervention: 20, control group: 20) were reached.

\section{Surgical Procedure}

Surgical operations were performed by three surgeons, one in each center. A vertical midline incision that does not extend above the umbilicus was performed. The ileal conduit was preferred as the diversion technique and extended lymph node dissection was also performed. Apart from early mobilization, ERAS protocols, as applied in clinical practice, were performed in all study participants from all three centers (intervention and control groups) as follows: Preoperative counseling and training, preoperative medical optimization, oral mechanical bowel preparation, preoperative diet, epidural analgesia, antimicrobial prophylaxis, and skin preparation, standard anesthesia protocol, preoperative liquid diet $8 \mathrm{~h}$ before surgery, urinary drainage, and postoperative multimodal analgesia practices (patientcontrolled analgesia was not performed in postoperative pain control). No postoperative complications were observed that might necessitate the patients to have an additional operation, as well as surgical mortality.

\section{Mobilization Procedure}

The patients were mobilized following the assessment of their suitability for mobilization as shown in Figure 1. Analgesic treatments were applied before the mobilization as prescribed by clinicians. The patients were mobilized under the supervision of researchers in accordance with the mobilization procedure in Figure 2. The exact definition of "early mobilization" in terms of the period after $\mathrm{RC}$ with ileal diversion is not reported in the literature. Therefore, the most appropriate time for mobilization was determined as the beginning of the next workday (on the first day after surgery), considering the factors, such as the time and length of operation, and the fact that the postoperative process coincided with the time of shift change, and the number of health personnel working in the clinic at night shift sufficient for safe mobilization. This period included the first $16 \mathrm{~h}$ after surgery assuming a normal operating procedure, and the period after $17 \mathrm{~h}$ was considered as late mobilization. Patients in the intervention group were mobilized within the $16 \mathrm{~h}$ postoperatively, whereas the mobilization of the control group was carried out after $17 \mathrm{~h}$ postoperatively. 


\section{Data Collection Method}

The case report form (CRF) and hospital anxiety and depression scale (HADS) were completed by the researchers using the faceto-face interview method and the 36-Item Short Form Survey (SF-36) OoL scale was filled by patients 1 day before surgery. Vital signs and peripheral blood glucose levels of patients before and after mobilization were recorded. HADS and SF-36 scales were applied after mobilization at the first and third months after surgery.

\section{Data Collection Tools}

CRF: This form consists of 14 questions that are related to sociodemographic and clinical features of patients, information about the operation process and postoperative healing process, and data on the patient's vital signs before and after mobilization.

HADS: The validity and reliability of the Turkish version of the HADS scale were developed in 1983 and tested by Aydemir et al. (12). The scale is used to measure the level and severity of anxiety and depression and determine the risk of anxiety and depression. There are, in total, 14 questions on the 4-point Likert scale; the odd numbers measure anxiety and the even numbers measure depression. The cut-off point of the scale is considered as $10 / 11$ for the anxiety subscale and $7 / 8$ for the depression subscale; those having higher scores are considered at risk.

SF-36 Quality of Life Scale: The SF-36 scale consists of 36 items and eight dimensions as follows: physical function, social functioning, role limitations due to physical problems, role

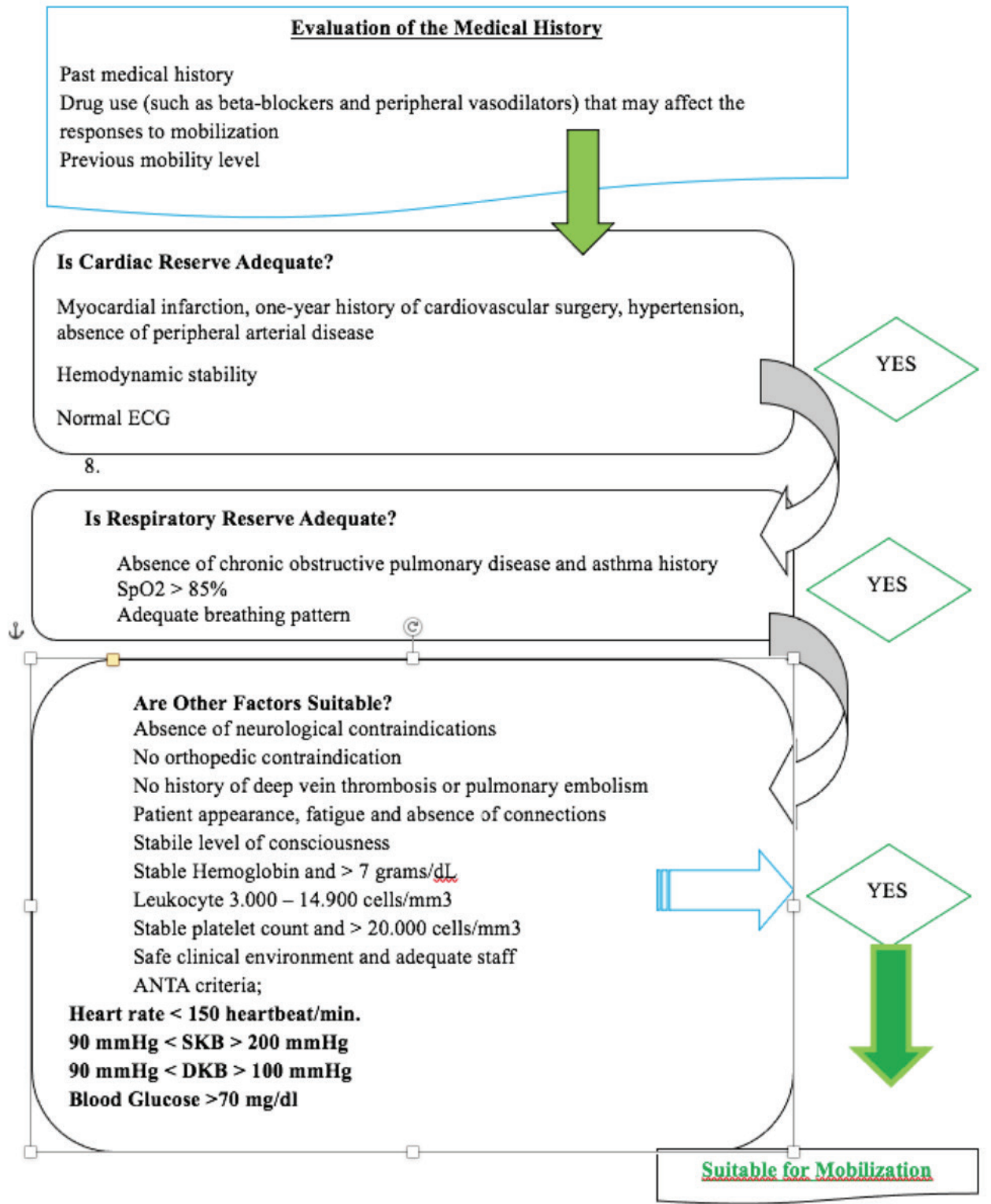

Figure 1. Mobilization suitability assessment guide 
limitations due to emotional problems, mental health, energy/ vitality, pain, and general perception of health. Zero-point from the subdimensions represent the worst health status, whereas 100 points show the best health status. Turkish validity and reliability test of The SF-36 scale was made by Kocyigit et al. (13).

\section{Ethical Considerations}

Written permission was obtained from the research centers before the research. The local ethics committee approval was obtained (izmir Tepecik Training and Research Hospital, approval number: 14/2, date: 30.10 .2014$)$. Written and verbal informed consent of patients was also obtained using an informed volunteer consent form.

\section{Statistical Analysis}

The Statistical Package for Social Sciences (IBM SPSS Statistics for Windows, Version 25.0. Armonk, NY: IBM Corp.) package program was used to evaluate the research data. The ShapiroWilk test was used to determine the normally distributed data.
The descriptive statistics, Student t-test, and Mann-Whitney $U$ test were used to analyze the data. The accepted level of significance was considered as $p<0.05$.

\section{Results}

The mean age of the patients was $64.8 \pm 10.3$ [minimummaximum (min-max): 48.0-80.0) years in the intervention group and $65.8 \pm 7.2$ (min-max: $52-80$ ] years in the control group. No significant difference was found between the groups in terms of sociodemographic characteristics, such as age, gender, smoking, and chronic disease $(p>0.05)$. Previous surgical history was present in 75\% $(n=15)$ of the intervention group, whereas $40 \%$ $(n=8)$ of the control group $(p=0.027)$. Postoperative complications were recorded according to the Clavien-Dindo classification system and were similar in frequency and incidence between the two groups. Complications, which were seen in both group participants, were limited to requiring medical interventions, such as antiemetics, analgesics, or antibiotics, according to the Clavien-Dindo classification system (Table 1).

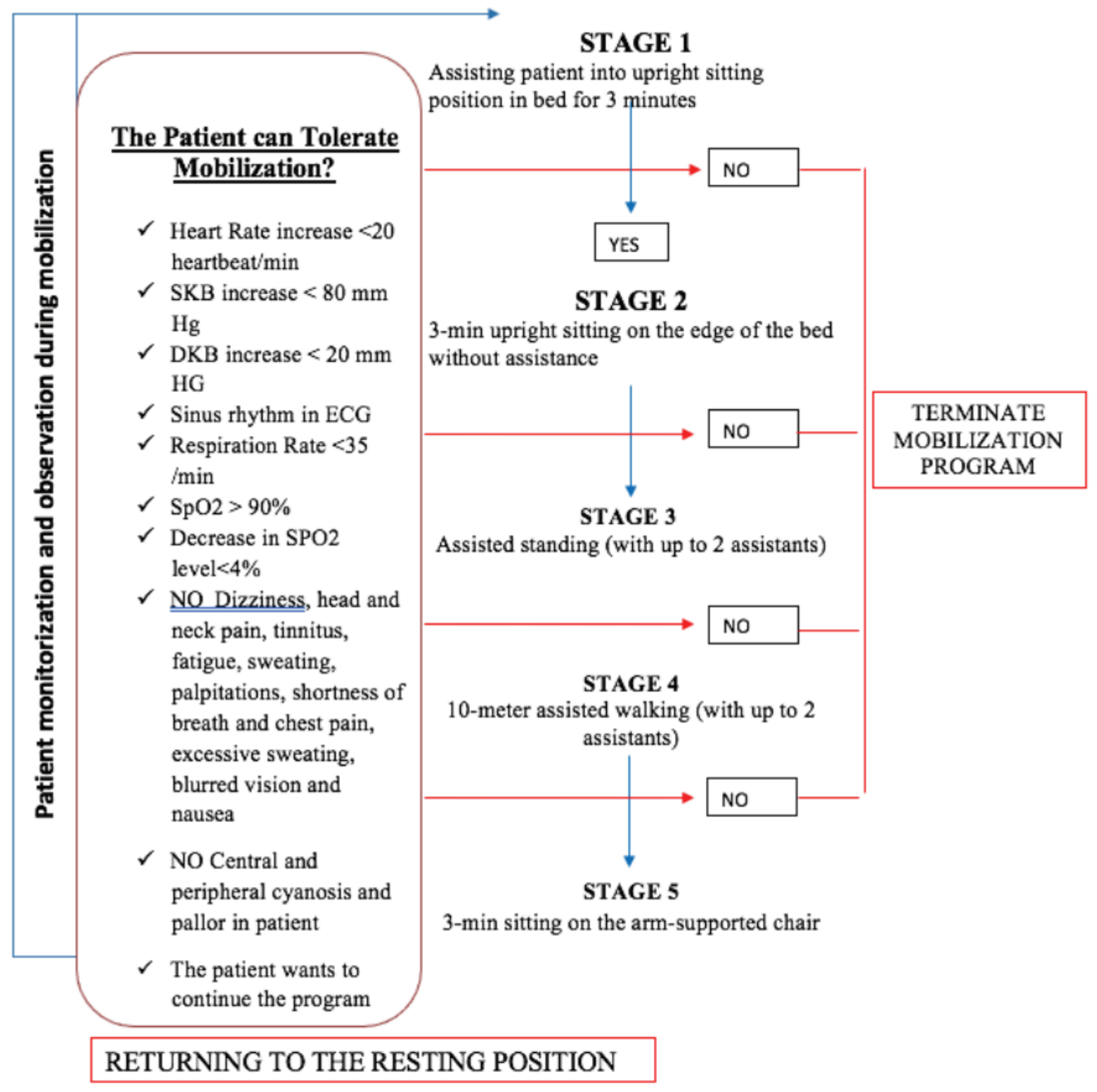

Figure 2. Mobilization application procedure 
The mean length of total hospital stay was $15.6 \pm 3.9$ (minmax: 10.0-25.0) days and 19.7 \pm 5.9 (min-max: 10.0-31.0) days in the intervention and control groups, respectively $(p=0.013)$. The mean duration of postoperative narcotic analgesic administration time was $4.3 \pm 3.8$ (min-max: 1.0-18.0) days in the intervention group, which was shorter than in the control group with statistically significant difference $(p=0.026)$. The mean first oral food intake, flatus, defecation, and nasogastric (NG) tube termination times in group 2 were $3.2 \pm 1.1$ (min: 1.0-max: 6.0) days, $3.4 \pm 1.4$ (min: 2.0-max: 6.0) days, $4.4 \pm 1.5$ (min: 3.0-max: 8.0) days, and 2.7 \pm 1.3 (min: 1.0-max: 5.0) days, respectively, which were earlier than the control group with statistically significant difference $(p=0.026, p=0.013, p=0.023$, and $p=0.013$ ). In the intervention group, the mean mobilization time in the first $24 \mathrm{~h}$ after surgery was $70.5 \pm 20.1$ (min: 40.0max: 105.0) $\min$, with statistically significant difference $(p<0.01)$ (Table 2).

The mean pulse rate after mobilization was $101.3 \pm 15.3$ (min: 76.0-max: 137.0) $\mathrm{min}$ in the control group and the mean value of SP02 without oxygen support was $96.1 \% \pm 2.3 \%$ (min-max: 92.0-100.0) in the intervention group, which were statistically significantly higher $(p=0.036$ and $p=0.001)$. The mean blood glucose value after mobilization was 109.8 \pm 24.3 (min: 90.0max: 176.0$) \mathrm{mg} / \mathrm{dL}$ in the intervention group and $139.3 \pm 41.7$ (min: 92.0-max: 234.0) $\mathrm{mg} / \mathrm{dL}$ in the control group, which was statistically significantly lower in the intervention group as shown in Table $3(p=0.009)$.

No significant difference was found between the groups in terms of SF-36 quality of life and HADS scale scores preoperatively ( $p>0.05$ ) (Table 4). The SF-36 subscale scores of physical function, physical role difficulty, and general perception of health were significantly higher in the intervention group in the first postoperative month $(p=0.016, p=0.041$, and $p=0.001)$. The mean of SF-36 vitality, mental health, social functioning, and general perception of health subscale scores were statistically significantly higher in the third postoperative month $(p<0.01$, $p<0.01, p=0.013$, and $p<0.01$ ) (Table 5).

\section{Discussion}

ERAS protocols do not only increases patient satisfaction and QoL but also improve clinical outcomes (14). The results related to sociodemographic variables, such as age and gender participants, were consistent with the literature (7,15-18). Considering the effects of sociodemographic and clinical characteristics on OoL and postoperative healing process, homogeneity of the research sample is of importance to not affect the results biasedly.

\begin{tabular}{|c|c|c|c|c|c|c|c|c|c|c|c|c|c|c|c|}
\hline \multicolumn{2}{|l|}{ Variable } & \multicolumn{2}{|c|}{$\begin{array}{l}\text { Intervention } \\
(n=20)\end{array}$} & \multicolumn{2}{|c|}{$\begin{array}{l}\text { Control } \\
(n=20)\end{array}$} & \multicolumn{2}{|c|}{ Test statistics } & \multicolumn{2}{|l|}{ Variable } & \multicolumn{2}{|c|}{$\begin{array}{l}\text { Intervention } \\
(\mathrm{n}=20)\end{array}$} & \multicolumn{2}{|c|}{$\begin{array}{l}\text { Control } \\
(n=20)\end{array}$} & \multicolumn{2}{|c|}{ Test statistics } \\
\hline \multirow{2}{*}{ Age groups } & $18-65$ years & 9 & 45.0 & 11 & 55.0 & \multirow{2}{*}{-0.624} & \multirow{2}{*}{$0.532^{b}$} & \multirow{2}{*}{ Gender } & Male & 19 & 95.0 & 19 & 95.0 & \multirow{2}{*}{0.000} & \multirow{2}{*}{$1.000^{b}$} \\
\hline & $66-80$ years & 11 & 55.0 & 9 & 45.0 & & & & Female & 1 & 5.0 & 1 & 5.0 & & \\
\hline $\begin{array}{l}\text { Marital } \\
\text { status }\end{array}$ & Single & 3 & 15.0 & 4 & 20.0 & -0.411 & $0.681^{b}$ & $\begin{array}{l}\text { Previous } \\
\text { any surgical } \\
\text { experience }\end{array}$ & No & 5 & 25.0 & 12 & 60.0 & -2.211 & $0.027^{b}$ \\
\hline \multirow{3}{*}{$\begin{array}{l}\text { Educational } \\
\text { background }\end{array}$} & Literate & 4 & 20.0 & 7 & 35.0 & \multirow{3}{*}{-0.452} & \multirow{3}{*}{$0.651^{b}$} & \multirow[b]{2}{*}{$\begin{array}{l}\text { Preoperative } \\
\text { training }\end{array}$} & Yes & 11 & 55.0 & 10 & 50.0 & \multirow[b]{2}{*}{-0.313} & \multirow[b]{2}{*}{$0.755^{b}$} \\
\hline & $\begin{array}{l}\text { Primary } \\
\text { education }\end{array}$ & 9 & 45.0 & 6 & 30.0 & & & & No & 9 & 45.0 & 10 & 50.0 & & \\
\hline & High school & 4 & 20.0 & 3 & 15.0 & & & $\begin{array}{l}\text { Postoperative } \\
\text { complication }\end{array}$ & Yes & 4 & 20.0 & 3 & 15.0 & -0.411 & $0.681^{b}$ \\
\hline $\begin{array}{l}\text { Body mass } \\
\text { index }\end{array}$ & Overweight & 6 & 30.0 & 6 & 40.0 & -0.805 & $0.421^{b}$ & & No & 16 & 80.0 & 13 & 65.0 & & \\
\hline Smokina & Smokes & 7 & 35.0 & 4 & 20.0 & -1049 & $0294^{b}$ & & & & & & & & \\
\hline smokıng & Gave up & 13 & 60.0 & 16 & 80.0 & -1.049 & $0.294^{\circ}$ & & & Inte & ention & $(n=$ & & lest sta & stics \\
\hline HT & Yes & 7 & 35.0 & 8 & 40.0 & -0322 & $0747^{b}$ & & & Mea & \pm SD & Mea & \pm SD & $t$ & \\
\hline HI & No & 13 & 65.0 & 12 & 60.0 & $-0.3 \angle 2$ & $0.14 /{ }^{\circ}$ & & & $(\min$ & nax) & (mir & $-\max )$ & $\mathrm{T}$ & $\mathbf{p}$ \\
\hline Diabetes & Yes & 5 & 25.0 & 4 & 20.0 & -0.374 & $0708^{b}$ & Ace/Year & & 64.8 & & & & 0.375 & $0710^{a}$ \\
\hline Dlabetes & No & 15 & 75.0 & 16 & 80.0 & $-0.3 / 4$ & $0.108^{\circ}$ & Age/Year & & $(48$. & 30.0) & (52. & $-80.0)$ & -0.315 & 0.110 \\
\hline
\end{tabular}


Preoperative anxiety, which negatively affects the $0 o L$, is more common in patients with previous surgical experience (3). Patients' expectations for the healing process also affect the OoL $(6,19)$. Our study revealed that the status of having previous surgical experience was higher in the intervention group; however, the expectations for recovery time, SF-36, and HADS scores were similar in both groups.

ERAS components have been reported to decrease the length of postoperative hospital stay $(7,16,20)$. Similar to the literature, our study revealed a significantly shorter length of postoperative and total hospital stay in the intervention group. However, the total hospital stay in our study was longer than in the literature $(7,17,20)$. In Turkey, government health payments cover the entire treatment process without being affected by the length of hospital stay. Therefore, most physicians prefer to follow the recovery process in the hospital. Additionally, as the sample of the study was 60 years or older, the anesthesia preparation process was conducted in the hospital. Therefore, preoperative hospital stay was higher in both groups compared to the literature $(15,18,21)$. Early mobilization may play a significant role in decreasing postoperative and total hospital stays.

Djaladat et al. (5) revealed that the complication incidence decreased in parallel with the length of hospital stay in patients who underwent ERAS. Moreover, Rivas et al. (21) revealed that the length of hospital stay was shortened without the risk of postoperative complications. The current study revealed no significant difference between the groups in terms of complication incidence rate. ERAS components that are jointly applied in research groups are thought to cause similarities between the groups.

\section{Table 2. Clinical features and data on the postoperative healing process}

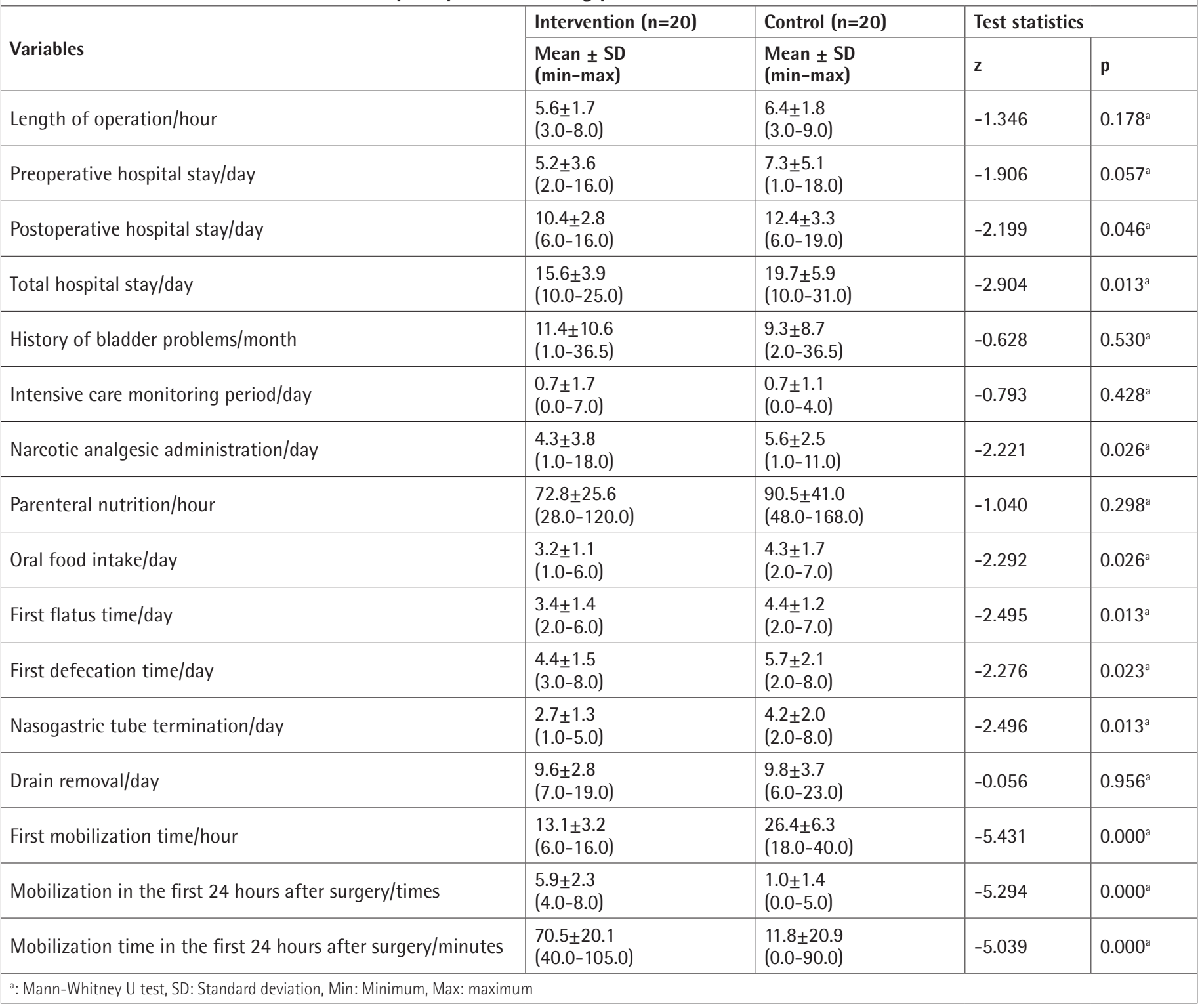


A study that examined the mobilization efficiency in the intensive care unit after organ transplantation revealed that the pulse rate was reduced to the normal limits after mobilization (22). Our study revealed that the pulse rate and blood glucose levels after mobilization were lower in the intervention group. Blood glucose levels may be higher in patients who remained inactive for a long time due to metabolic stress that may occur after the surgery. Our study revealed that the glucose levels of all patients were stable before the surgery. Blood glucose value is decreased in the intervention group due to the increased energy requirement of muscle tissue during mobilization, increased use of glucose, and increased insulin sensitivity along with mobilization. We believe that early mobilization can be effective in terms of early hyperglycemia control that is induced by metabolic stress and hepatic glucose metabolism regulation.

Mobilization is of great importance in terms of increasing muscle strength and function, decreasing the level of dependence, and providing cardiorespiratory healing and gravitational stimulation after major surgery without complication $(2,3)$. Postoperative early mobilization was reported to increase oxygen transport and reduce the incidence of pulmonary complications (23). Our study revealed that the values of $\mathrm{SPO}_{2}$ with and without oxygen support measured after mobilization were significantly higher in the intervention group in parallel with the literature and no early-stage pulmonary complications were observed in both groups.

Semerjian et al. (20) revealed that patients were mobilized at night after surgery and Persson et al. (11) and Arumainayagam et al. (24) revealed that patients were mobilized within the first $24 \mathrm{~h}(11,20,24)$. Guan et al. (16) revealed that patients were encouraged to get out of bed at least four times a day, $24 \mathrm{~h}$ after surgery (16). Dutton et al. (17) revealed that patients were sitting up on the bed in the first $48 \mathrm{~h}$ after surgery and the walking exercises were started after $48 \mathrm{~h}$. Mukhtar et al. (18) revealed that patients were mobilized at least $6 \mathrm{~h}$ a day after the first mobilization. Retrospective $(17,18,21,24)$ and prospective studies $(7,8,15,20)$ on ERAS protocols in RC treatment were analyzed; early mobilization procedure was reported to be

\begin{tabular}{|c|c|c|c|c|c|}
\hline \multirow[b]{2}{*}{ Parameter } & \multirow{2}{*}{$\begin{array}{l}\text { Before/after } \\
\text { mobilization }\end{array}$} & \multirow{2}{*}{\begin{tabular}{|l} 
Intervention $(\mathrm{n}=20)$ \\
$\begin{array}{l}\text { Mean } \pm \text { SD } \\
(\min -\max )\end{array}$ \\
\end{tabular}} & \multirow{2}{*}{$\begin{array}{l}\text { Control }(n=20) \\
\text { Mean } \pm \text { SD } \\
(\text { min-max })\end{array}$} & \multicolumn{2}{|c|}{ Test statistics } \\
\hline & & & & $z / t$ & p \\
\hline \multirow{2}{*}{ Systolic blood pressure/mmHg } & Before & $\begin{array}{l}128.7 \pm 16.9 \\
(90.0-152.0) \\
\end{array}$ & \begin{tabular}{|l}
$126.7 \pm 17.8$ \\
$(95.0-160.0)$ \\
\end{tabular} & -0.298 & $0.766^{\mathrm{a}}$ \\
\hline & After & $\begin{array}{l}117.7 \pm 15.12 \\
(90.0-140.0) \\
\end{array}$ & $\begin{array}{l}120.6 \pm 22.6 \\
(90.0-170.0) \\
\end{array}$ & -0.477 & $0.636^{b}$ \\
\hline \multirow{2}{*}{ Diastolic blood pressure $/ \mathrm{mmHg}$} & Before & $\begin{array}{l}77.7 \pm 14.2 \\
(40.0-94.0) \\
\end{array}$ & \begin{tabular}{|l|}
$72.7 \pm 9.2$ \\
$(60.0-91.0)$ \\
\end{tabular} & 1.334 & $0.190^{b}$ \\
\hline & After & \begin{tabular}{|l|}
$69.5 \pm 6.4$ \\
$(58.0-80.0)$ \\
\end{tabular} & \begin{tabular}{|l|}
$71.1 \pm 10.6$ \\
$(50.0-97.0)$ \\
\end{tabular} & -0.577 & $0.568^{\mathrm{b}}$ \\
\hline \multirow{2}{*}{ Pulse/min. } & Before & \begin{tabular}{|l|}
$85.9 \pm 12.6$ \\
$(68.0-109.0)$
\end{tabular} & \begin{tabular}{|l|}
$83.5 \pm 16.0$ \\
$(60.0-116.0)$
\end{tabular} & 0.515 & $0.609^{b}$ \\
\hline & After & \begin{tabular}{|l|}
$92.0 \pm 11.5$ \\
$(72.0-118.0)$ \\
\end{tabular} & $\begin{array}{l}101.3 \pm 15.3 \\
(76.0-137.0) \\
\end{array}$ & -2.174 & $0.036^{b}$ \\
\hline \multirow{2}{*}{ Fever $/{ }^{\circ} \mathrm{C}$} & Before & $\begin{array}{l}36.6 \pm 0.3 \\
(36.0-37.6)\end{array}$ & $\begin{array}{l}36.6 \pm 0.4 \\
(36.0-37.7)\end{array}$ & -0.399 & $0.690^{\mathrm{a}}$ \\
\hline & After & $\begin{array}{l}36.5 \pm 0.2 \\
(36.2-36.8)\end{array}$ & $\begin{array}{l}36.6 \pm 0.4 \\
(36.2-37.6)\end{array}$ & -0.302 & $0.763^{\mathrm{a}}$ \\
\hline \multirow{2}{*}{$\mathrm{SPO}_{2} /$ with $\mathrm{O}_{2}$ support (\%) } & Before & $\begin{array}{l}97.1 \pm 1.8 \\
(94.0-100.0)\end{array}$ & \begin{tabular}{|l|}
$96.8 \pm 1.6$ \\
$(94.0-99.0)$
\end{tabular} & -0.422 & $0.673^{\mathrm{a}}$ \\
\hline & After & \begin{tabular}{|l}
$98.9 \pm 1.8$ \\
$(92.0-100.0)$
\end{tabular} & \begin{tabular}{|l|}
$96.8 \pm 1.6$ \\
$(94.0-99.0)$
\end{tabular} & -4.005 & $0.000^{\mathrm{a}}$ \\
\hline \multirow{2}{*}{$\mathrm{SPO}_{2} /$ without $\mathrm{O}_{2}$ support $(\%)$} & Before & $\begin{array}{l}92.6 \pm 2.9 \\
(88.0-100.0)\end{array}$ & $\begin{array}{l}92.6 \pm 2.7 \\
(88.0-97.0)\end{array}$ & -0.096 & $0.923^{\mathrm{a}}$ \\
\hline & After & \begin{tabular}{|l|}
$96.1 \pm 2.3$ \\
$(92.0-100.0)$ \\
\end{tabular} & $\begin{array}{l}93.3 \pm 2.5 \\
(89.0-98.0) \\
\end{array}$ & 3.733 & $0.001^{b}$ \\
\hline \multirow{2}{*}{ Blood glucose (mg/dL) } & Before & \begin{tabular}{|l|}
$131.4 \pm 27.0$ \\
$(107.0-212.0)$
\end{tabular} & \begin{tabular}{|l|}
$148.5 \pm 42.7$ \\
$(98.0-248.0)$
\end{tabular} & -1.382 & $0.167^{\mathrm{a}}$ \\
\hline & After & $\begin{array}{l}109.8 \pm 24.3 \\
(90.0-176.0) \\
\end{array}$ & \begin{tabular}{|l|}
$139.3 \pm 41.7$ \\
$(92.0-234.0)$
\end{tabular} & -2.441 & $0.015^{\mathrm{a}}$ \\
\hline
\end{tabular}


applied; however, no information was given concerning the mobilization process in terms of its time, duration, and method. Our study revealed that patients in the intervention group were mobilized within the first $16 \mathrm{~h}$ following a standard mobilization procedure differently from the literature. Factors, such as the length of surgery and the presence of adequate medical staff for safe mobilization after surgery, were considered.

The literature reported that regaining regular intestinal functions took a shorter time in patients who underwent ERAS protocol $(4,20)$. NG tube was reported to be removed in $2.0 \pm 0.3$ days by Mukhtar et al. (18); on the first day after the surgery by Arumainayagam et al. (24); and immediately after the surgery by Saar et al. $(15,18,24)$. The first defecation time in the literature was reported as $6.1 \pm 0.3 /$ days by Mukhtar et al. (18) and $2.6 \pm 0.9 /$ days by Saar et al. (15), Persson et al. (11) revealed that the time of the first bowel movement was 2 days earlier in the ERAS group (11). Moreover, Frees et al. (7) pointed out that the first defecation time was shorter in enterally fed patients. Our study revealed that the first defecation time was $4.4 \pm 1.5$ days (intervention group), similar to the results of Frees et al. (7) and Mukhtar et al. (18) and it was 1.5 days shorter in the intervention group (5.7 \pm 2.1 days/control group) as in Persson et al. (11). Our findings suggest that early mobilization contributes to the early motility of bowel and NG tube removal.
Karl et al. (8) revealed that $\mathrm{OoL}$ was better on the third and seventh days after surgery in patients who underwent ERAS protocols. Porserud et al. (10) revealed that patients who were included in the exercise program had higher scores at functional capacity and physical area dimensions of QoL. Our study revealed that QoL was significantly better in the intervention group in terms of physical function, physical role difficulty, and general perception of health in the first month. In the third month after surgery, the scores of physical and emotional role difficulty, vitality, mental health, and general perception of health subdimensions were significantly better in the intervention group. RC treatment has a significant effect on $\mathrm{OoL}$ in patients who underwent $\mathrm{RC}$ in the early postoperative period. The disappearance of the difference that was observed in the physical function subdimension of $\mathrm{QoL}$ in the first month could be explained by the healing effect of the ERAS components jointly applied in both groups. Standardized ERAS protocols improve patient satisfaction and $\mathrm{OoL}$ in addition to improved clinical patient outcomes (6). Additionally, the inclusion of patients' relatives in the care planning will have positive effects on the healing process (25).

Rivas et al. (21) revealed that ERAS may have a positive effect on patients who underwent $\mathrm{RC}$ and only with multidisciplinary teamwork. Our multicenter study revealed that great importance

Table 4. Preoperative SF-36 quality of life and HADS scale score distributions

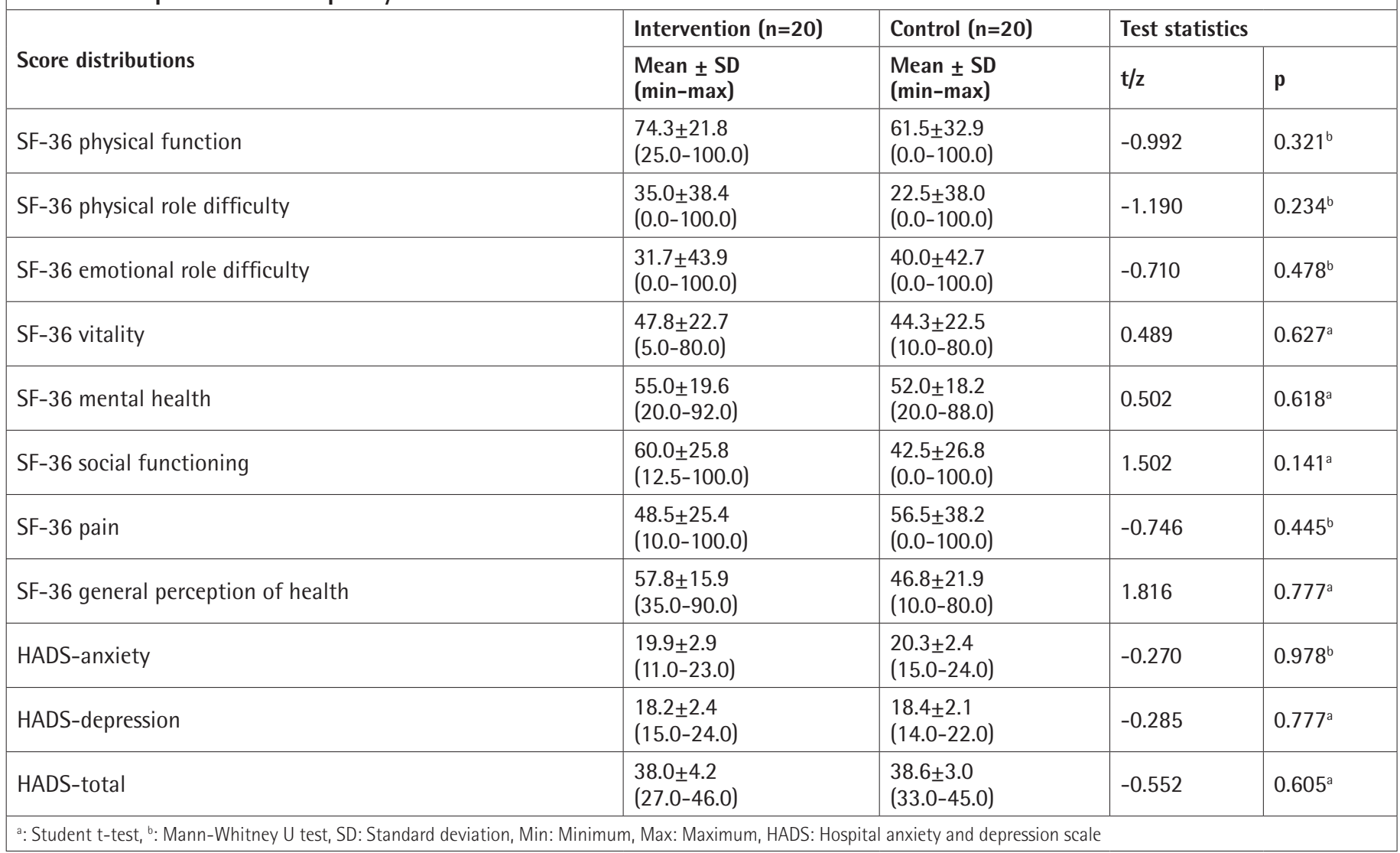




\begin{tabular}{|c|c|c|c|c|c|}
\hline \multirow{2}{*}{\multicolumn{2}{|c|}{$\begin{array}{l}\text { Table 5. Postoper } \\
\text { Score distribution }\end{array}$}} & \multirow{3}{*}{\begin{tabular}{|l|} 
Intervention \\
$\begin{array}{l}\text { Mean } \pm \text { SD } \\
\text { (min-max) }\end{array}$ \\
$41.0 \pm 19.4$ \\
$(15.0-70.0)$ \\
\end{tabular}} & \multirow{3}{*}{$\begin{array}{l}\text { Control } \\
\begin{array}{l}\text { Mean } \pm \text { SD } \\
(\min -\max )\end{array} \\
26.8 \pm 16.2 \\
(0.0-55.0) \\
\end{array}$} & \multicolumn{2}{|c|}{ Test statistics } \\
\hline & & & & \multirow{2}{*}{\begin{tabular}{|l}
$z$ \\
-2.409
\end{tabular}} & \multirow{2}{*}{$\begin{array}{l}p \\
0.016^{a}\end{array}$} \\
\hline \multirow{11}{*}{ 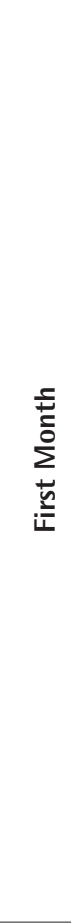 } & SF-36 physical functioning & & & & \\
\hline & SF-36 physical role difficulty & $\begin{array}{l}11.3 \pm 12.8 \\
(0.0-25.0)\end{array}$ & $\begin{array}{l}3.8 \pm 9.2 \\
(0.0-25.0)\end{array}$ & -2.044 & $0.041^{\mathrm{a}}$ \\
\hline & SF-36 emotional role difficulty & $\begin{array}{l}31.7 \pm 39.7 \\
(0.0-100.0)\end{array}$ & $\begin{array}{l}13.3 \pm 22.7 \\
(0.0-66.7) \\
\end{array}$ & -1.406 & $0.160^{\mathrm{a}}$ \\
\hline & SF-36 vitality & $\begin{array}{l}32.5 \pm 21.2 \\
(10.0-85.00)\end{array}$ & $\begin{array}{l}23.8 \pm 22.4 \\
(0.0-60.0)\end{array}$ & -1.813 & $0.070^{\mathrm{a}}$ \\
\hline & SF-36 mental health & $\begin{array}{l}53.4 \pm 20.4 \\
(28.0-96.0)\end{array}$ & $\begin{array}{l}41.6 \pm 17.8 \\
(20 .-68.0)\end{array}$ & -1.820 & $0.069^{\mathrm{a}}$ \\
\hline & SF-36 social functioning & $\begin{array}{l}21.3 \pm 12.2 \\
(0.0-50.0)\end{array}$ & $\begin{array}{l}15.0 \pm 12.6 \\
(0.0-37.5)\end{array}$ & -1.501 & $0.133^{\mathrm{a}}$ \\
\hline & SF-36 pain & $\begin{array}{l}53.0 \pm 13.7 \\
(32.5-62.5) \\
\end{array}$ & \begin{tabular}{|l|}
$54.6 \pm 13.1$ \\
$(32.5-77.5)$ \\
\end{tabular} & -0.260 & $0.795^{\mathrm{a}}$ \\
\hline & SF-36 general perception of health & $\begin{array}{l}38.8 \pm 11.7 \\
(20.8-60.6) \\
\end{array}$ & $\begin{array}{l}21.9 \pm 16.1 \\
(1.0-46.0) \\
\end{array}$ & -3.243 & $0.001^{\mathrm{a}}$ \\
\hline & HADS-anxiety & $\begin{array}{l}21.4 \pm 2.1 \\
(16.0-23.0) \\
\end{array}$ & \begin{tabular}{|l}
$20.4 \pm 3.1$ \\
$(14.0-24.0)$ \\
\end{tabular} & -0.575 & $0.565^{\mathrm{a}}$ \\
\hline & HADS-depression & $\begin{array}{l}20.1 \pm 2.1 \\
(17.0-24.0)\end{array}$ & \begin{tabular}{|l}
$20.3 \pm 2.3$ \\
$(18.0-24.0)$ \\
\end{tabular} & -0.151 & $0.880^{\mathrm{a}}$ \\
\hline & HADS-total & $\begin{array}{l}41.4 \pm 2.9 \\
(35.0-45.0)\end{array}$ & \begin{tabular}{|l|}
$40.7 \pm 2.6$ \\
$(35.0-45.0)$ \\
\end{tabular} & -0.589 & $0.556^{\mathrm{a}}$ \\
\hline \multirow{11}{*}{ 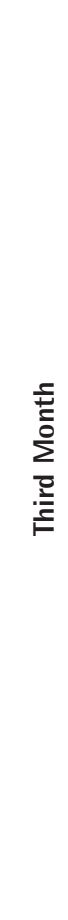 } & SF-36 physical functioning & $\begin{array}{l}74.3 \pm 15.9 \\
(40.0-90.0)\end{array}$ & $\begin{array}{l}66.0 \pm 16.0 \\
(40.0-100.0)\end{array}$ & -1.922 & $0.055^{\mathrm{a}}$ \\
\hline & SF-36 physical role difficulty & $\begin{array}{l}70.1 \pm 31.0 \\
(0.0-100.0)\end{array}$ & \begin{tabular}{|l|}
$42.5 \pm 28.2$ \\
$(0.0-100.0)$ \\
\end{tabular} & -2.838 & $0.005^{\mathrm{a}}$ \\
\hline & SF-36 emotional role difficulty & $\begin{array}{l}73.9 \pm 40.8 \\
(0.0-100.0)\end{array}$ & \begin{tabular}{|l|}
$45.0 \pm 39.4$ \\
$(0.0-100.0)$ \\
\end{tabular} & -2.765 & $0.006^{\mathrm{a}}$ \\
\hline & SF-36 vitality & $\begin{array}{l}66.3 \pm 16.1 \\
(20.0-85.0)\end{array}$ & $\begin{array}{l}41.0 \pm 21.1 \\
(5.0-70.0) \\
\end{array}$ & -3.931 & $0.000^{\mathrm{a}}$ \\
\hline & SF-36 mental health & $\begin{array}{l}83.4 \pm 11.8 \\
(40.0-100.0)\end{array}$ & \begin{tabular}{|l|}
$60.8 \pm 20.5$ \\
$(36.0-92.0)$ \\
\end{tabular} & -3.699 & $0.000^{\mathrm{a}}$ \\
\hline & SF-36 social functioning & $\begin{array}{l}65.0 \pm 20.5 \\
(12.5-87.5)\end{array}$ & $\begin{array}{l}48.8 \pm 18.1 \\
(25.0-87.5)\end{array}$ & -2.486 & $0.013^{\mathrm{a}}$ \\
\hline & SF-36 pain & $\begin{array}{l}49.3 \pm 2.4 \\
(40.0-50.0) \\
\end{array}$ & \begin{tabular}{|l|}
$53.6 \pm 9.7$ \\
$(45.0-77.5)$ \\
\end{tabular} & -1.633 & $0.112^{\mathrm{a}}$ \\
\hline & SF-36 general perception of health & $\begin{array}{l}64.3 \pm 15.5 \\
(20.0-80.0)\end{array}$ & $\begin{array}{l}38.0 \pm 15.9 \\
(20.0-80.0)\end{array}$ & -4.073 & $0.000^{\mathrm{a}}$ \\
\hline & HADS-anxiety & $\begin{array}{l}22.3 \pm 1.7 \\
(17.0-25.0)\end{array}$ & $\begin{array}{l}20.6 \pm 2.9 \\
(15.0-25.0) \\
\end{array}$ & -1.588 & $0.112^{\mathrm{a}}$ \\
\hline & HADS-depression & $\begin{array}{l}18.0 \pm 1.8 \\
(14.0-23.0)\end{array}$ & \begin{tabular}{|l|}
$18.0 \pm 1.4$ \\
$(16.0-23.0)$ \\
\end{tabular} & -0.086 & $0.932^{\mathrm{a}}$ \\
\hline & HADS-total & $\begin{array}{l}40.3 \pm 2.4 \\
(34.0-46.0)\end{array}$ & \begin{tabular}{|l|}
$38.6 \pm 3.4$ \\
$(33.0-45.0)$ \\
\end{tabular} & -1.282 & $0.200^{\mathrm{a}}$ \\
\hline
\end{tabular}

was attached to the multidisciplinary teamwork for the surgeons who perform the surgery and the nurses responsible for clinical care to cooperate with the dieticians, physiotherapists, and all other health professionals.

\section{Study Limitations}

The limited number of patients for 3 years due to patients who had to be excluded from the study can be considered as the limitation of the current study. Additionally, the intervention 
group was encouraged for early mobilization by the research team, which created a sense of exclusiveness and worthiness in the patients and their relatives, thus they were more actively involved in the process. More frequent communication with the researcher upon the request of the patients in the intervention group might have positively affected the responses to the surveys in the long run.

\section{Conclusion}

Early mobilization could be safely performed in patients who underwent $\mathrm{RC}$ and ileal diversion following the standard procedure, which has positively contributed to the healing process and improved their QoL.

Standardized ERAS protocols are needed to provide optimal supportive care in patients who underwent RC. More multicenter prospective randomized controlled studies with larger samplings are needed to evaluate different components of ERAS protocol in different countries.

\section{Ethics}

Ethics Committee Approval: The local ethics committee approval was obtained (Izmir Tepecik Training and Research Hospital, approval number: 14/2, date: 30.10 .2014$)$.

Informed Consent: Those who signed the informed consent form were included in the study.

Peer-review: Externally peer-reviewed.

\section{Authorship Contributions}

Surgical and Medical Practices: Ö.Ç., T.M., G.A., Concept: S.V., Ö.Ç., T.M., G.A., H.B., Design: S.V., Ö.Ç., T.M., G.A., H.B., Data Collection or Processing: S.V., Ö.Ç., T.M., G.A., Analysis or Interpretation: S.V., Ö.Ç., H.B., Literature Search: S.V., Ö.Ç., T.M., G.A., H.B., Writing: S.V., Ö.Ç., T.M., G.A., H.B.

Conflict of Interest: No conflict of interest was declared by the authors.

Financial Disclosure: The authors declare that they have no relevant financial.

\section{References}

1. Siracusano $S$, D'Elia $C$, Cerruto MA, Saleh 0 , Serni $S$, Gacci M, Ciciliato $S$, Simonato A, Porcaro A, DE Marco V, Talamini R, Toffoli L, Visalli F, Niero M, Lonardi C, Imbimbo C, Verze $P$, Mirone V, Racioppi M, lafrate $M$, Cacciamani G, DE Marchi D, Bassi P, Artibani W. Quality of Life in Patients with Bladder Cancer Undergoing lleal Conduit: A Comparison of Women Versus Men. In Vivo 2018:32:139-143.

2. Moschini M, Stabile A, Mattei A, Montorsi F, Cathelineau X, Sanchez-Salas $R$. Enhanced recovery after surgery (ERAS) in radical cystectomy patients: from consensus to evidences. Int Braz J Urol 2019;45:655-657.
3. Visioni A, Shah R, Gabriel E, Attwood K, Kukar M, Nurkin S. Enhanced Recovery After Surgery for Noncolorectal Surgery?: A Systematic Review and Meta-analysis of Major Abdominal Surgery. Ann Surg 2018;267:5765.

4. Tyson MD, Chang SS. Enhanced Recovery Pathways Versus Standard Care After Cystectomy: A Meta-analysis of the Effect on Perioperative Outcomes. Eur Urol 2016;70:995-1003.

5. Djaladat H, Katebian B, Bazargani ST, Miranda G, Cai J, Schuckman AK, Daneshmand S. 90-Day complication rate in patients undergoing radical cystectomy with enhanced recovery protocol: a prospective cohort study. World J Urol 2017;35:907-911

6. Aarts $M A$, Rotstein $O D$, Pearsall $E A$, Victor JC, Okrainec $A$, McKenzie $M$, McCluskey SA, Conn LG, McLeod RS; iERAS group. Postoperative ERAS Interventions Have the Greatest Impact on Optimal Recovery: Experience With Implementation of ERAS Across Multiple Hospitals. Ann Surg 2018;267:992-997.

7. Frees SK, Aning J, Black $P$, Struss $W$, Bell R, Chavez-Munoz C, Gleave $M$, So Al. A prospective randomized pilot study evaluating an ERAS protocol versus a standard protocol for patients treated with radical cystectomy and urinary diversion for bladder cancer. World J Urol 2018;36:215-220.

8. Karl A, Buchner A, Becker A, Staehler M, Seitz M, Khoder W, Schneevoigt $B$, Weninger E, Rittler P, Grimm T, Gratzke C, Stief C. A new concept for early recovery after surgery for patients undergoing radical cystectomy for bladder cancer: Results of a prospective randomized study. J Urol 2014;191:335-340.

9. Cerantola $Y$, Valerio $M$, Persson $B$, Jichlinski $P$, Ljungqvist $O$, Hubner $M$ Kassouf W, Muller S, Baldini G, Carli F, Naesheimh T, Ytrebo L, Revhaug A, Lassen $K_{1}$ Knutsen T, Aarsether E, Wiklund P, Patel HRH. Guidelines for perioperative care after radical cystectomy for bladder cancer: Enhanced recovery after surgery (ERAS $\left.{ }^{\circledR}\right)$ society recommendations. Clin Nutr 2013;32:879-887.

10. Porserud A, Sherif A, Tollbäck A. The effects of a physical exercise programme after radical cystectomy for urinary bladder cancer. A pilot randomized controlled trial. Clin Rehabil 2014;28:451-459.

11. Persson B, Carringer $M$, Andrén 0 , Andersson SO, Carlsson J, Ljungqvist 0 . Initial experiences with the enhanced recovery after surgery (ERAS) protocol in open radical cystectomy. Scand J Urol 2015;49:302-307.

12. Aydemir O, Guvenir T, Kuey L, Kultur S. Validity and reliability of Turkish version of hospital anxiety and depression scale. Türk Psikiyatri Dergisi 1997:84:280-287.

13. Kocyigit H, Aydemir O, Olmez N, Memis A. Reliability and Validity of the Turkish Version of Short Form-36 (SF-36). İlaç ve Tedavi Dergisi 1999.

14. Lau CS, Chamberlain RS. Enhanced Recovery After Surgery Programs Improve Patient Outcomes and Recovery: A Meta-analysis. World J Surg 2017;41:899-913.

15. Saar M, OhImann CH, Siemer S, Lehmann J, Becker F, Stöckle M, Kamradt J. Fast-track rehabilitation after robot-assisted laparoscopic cystectomy accelerates postoperative recovery. BJU Int 2013;112:E99-106.

16. Guan X, Liu L, Lei X, Zu X, Li Y, Chen M, Wang L, Qi L. CORRIGENDUM: A Comparative Study of Fast-Track Versus Conventional Surgery in Patients Undergoing Laparoscopic Radical Cystectomy and Ileal Conduit Diversion: Chinese Experience. Sci Rep 2015;5:8177.

17. Dutton TJ, Daugherty MO, Mason RG, McGrath JS. Implementation of the Exeter enhanced recovery programme for patients undergoing radical cystectomy. BJU Int 2014;113:719-725.

18. Mukhtar S, Ayres BE, Issa R, Swinn MJ, Perry MJ. Challenging boundaries: an enhanced recovery programme for radical cystectomy. Ann R Coll Surg Engl 2013;95:200-206

19. Singh V, Yadav R, Sinha RJ, Gupta DK. Prospective comparison of qualityof-life outcomes between ileal conduit urinary diversion and orthotopic 
neobladder reconstruction after radical cystectomy: a statistical model. BJU Int 2014;113:726-732.

20. Semerjian A, Milbar $N$, Kates $M$, Gorin MA, Patel HD, Chalfin HJ, Frank SM, Wu CL, Yang WW, Hobson D, Robertson L, Wick E, Schoenberg MP, Pierorazio PM, Johnson MH, Stimson CJ, Bivalacqua TJ. Hospital Charges and Length of Stay Following Radical Cystectomy in the Enhanced Recovery After Surgery Era. Urology 2018;111:86-91.

21. Rivas JG, Alonso y Gregorio S, Ledo JC, Orejón RU, Doslada PU, Sebastián JD, Gomez AT, de la Pena Barthel JJ. Early recovery protocol in patients undergoing laparoscopic radical cystectomy Urol Sci 2017;28:2-5.

22. Senduran M, Yurdalan SU, Karadibak D, Gunerli A. Haemodynamic effects of physiotherapy programme in intensive care unit after liver transplantation. Disabil Rehabil 2010;32:1461-1466.
23. Kirkeby-Garstad I, Sellevold OF, Stenseth R SE. Mixed venous oxygen desaturation during early mobilization after coronary artery bypass surgery. Acta Anaesthesiol Scand 2005;49:827-834.

24. Arumainayagam N, McGrath J, Jefferson KP, Gillatt DA. Introduction of an enhanced recovery protocol for radical cystectomy. BJU Int 2008;101:698701.

25. Baris N, Karabacak U. The inpatients' relatives' perception of the nursing role. J Marmara Univ Inst Heal Sci 2013;3:131. 